\title{
Citrin deficiency mimicking mitochondrial depletion syndrome
}

\author{
S. C. Grünert ${ }^{1 *}$ (D), A. Schumann ${ }^{1}$, P. Freisinger ${ }^{2}$, S. Rosenbaum-Fabiann ${ }^{1}$, M. Schmidts', A. J. Mueller ${ }^{3}$, S. Beck-Wödl ${ }^{3}$, \\ T. B. Haack ${ }^{3,4}$, H. Schneider ${ }^{1}$, H. Fuchs' ${ }^{1}$, U. Teufel ${ }^{1}$, G. Gramer', L. Hannibal ${ }^{6}$ and U. Spiekerkoetter ${ }^{1}$
}

\begin{abstract}
Background: Neonatal intrahepatic cholestasis caused by citrin deficiency (CD) is a rare inborn error of metabolism due to variants in the SLC25A13 gene encoding the calcium-binding protein citrin. Citrin is an aspartate-glutamate carrier located within the inner mitochondrial membrane.

Case presentation: We report on two siblings of Romanian-Vietnamese ancestry with citrin deficiency. Patient 1 is a female who presented at age 8 weeks with cholestasis, elevated lactate levels and recurrent severe hypoglycemia. Diagnosis was made by whole exome sequencing and revealed compound heterozygosity for the frameshift variant c.852_855del, p.Met285Profs*2 and a novel deletion c.(69+1_70-1)_(212+1_231-1)del in SLC25A13. The girl responded well to dietary treatment with a lactose-free, MCT-enriched formula. Her younger brother (Patient 2) was born 1 year later and also found to be carrying the same gene variants. Dietary treatment from birth was able to completely prevent clinical manifestation until his current age of 4.5 months.

Conclusions: As CD is a well-treatable disorder it should be ruled out early in the differential diagnosis of neonatal cholestasis. Due to the combination of hepatopathy, lactic acidosis and recurrent hypoglycemia the clinical presentation of CD may resemble hepatic mitochondrial depletion syndrome.
\end{abstract}

Keywords: Citrin deficiency, Neonatal cholestasis, Hypoglycemia, Newborn screening, Urea cycle defect, SLC25A13

\section{Background}

Citrin deficiency $(\mathrm{CD})$ is an autosomal recessive inborn error of metabolism caused by variants in the SLC25A13 gene [1-3]. Citrin is an aspartate-glutamate carrier located within the inner mitochondrial membrane and mainly expressed in the liver, kidney, heart and small intestine $[4,5]$. Its role to transport aspartate from the mitochondrial matrix to the cytosol is important for several metabolic pathways including protein, nucleotide and urea synthesis as well as gluconeogenesis from lactate and the translocation of cytosolic NADH reducing equivalents into the mitochondria via the malate-

\footnotetext{
* Correspondence: sarah.gruenert@uniklinik-freiburg.de

1 Department of General Paediatrics, Adolescent Medicine and Neonatology, Medical Centre-University of Freiburg, Faculty of Medicine, Mathildenstraße 1, 79106 Freiburg, Germany

Full list of author information is available at the end of the article
}

aspartate shuttle [4]. While CD is relatively common in East Asian populations, especially in Japan, the incidence in Europe is extremely low [2], although CD is a panethnic disease, and subjects have been reported from different ethnicities [6-10]. Three age-dependent clinical phenotypes are associated with $\mathrm{CD}$, namely 1 ) neonatal intrahepatic cholestasis caused by citrin deficiency (NICCD) usually manifesting in newborns or infants, 2) failure to thrive and dyslipidemia caused by citrin deficiency (FTTDCD), beyond age 1 year and 3) citrullinemia type II (CTLN2) with usually sudden manifestation between ages 20 and 50 years [2]. Children with NICCD often have a history of low birth weight with growth retardation. The disease is clinically characterised by intrahepatic cholestasis, hepatomegaly, diffuse fatty liver, variable liver dysfunction, hypoproteinemia, coagulopathy due to impaired hepatic synthesis of coagulation

(c) The Author(s). 2020 Open Access This article is licensed under a Creative Commons Attribution 4.0 International License, which permits use, sharing, adaptation, distribution and reproduction in any medium or format, as long as you give appropriate credit to the original author(s) and the source, provide a link to the Creative Commons licence, and indicate if changes were made. The images or other third party material in this article are included in the article's Creative Commons licence, unless indicated otherwise in a credit line to the material. If material is not included in the article's Creative Commons licence and your intended use is not permitted by statutory regulation or exceeds the permitted use, you will need to obtain permission directly from the copyright holder. To view a copy of this licence, visit http://creativecommons.org/licenses/by/4.0/ The Creative Commons Public Domain Dedication waiver (http://creativecommons.org/publicdomain/zero/1.0/) applies to the data made available in this article, unless otherwise stated in a credit line to the data. 
factors, haemolytic anemia and hypoglycemia [2, 11, 12]. NICCD is generally not severe, however, few patients required liver transplantation [13, 14], and fatal cases have been reported [15]. Many patients display markedly elevated galactose levels at the age of 1 month and the use of lactose-free milk should be considered in patients with hypergalactosemia [16]. Dietetic treatment with use of medium-chain triglyceride- (MCT-) enriched formulas has also been recommended [2, 16]. Interestingly, children with $C D$ show a strong preference for proteinrich and lipid-rich foods and a natural aversion to sugarand carbohydrate-rich foods [4, 16, 17]. Some patients with NICCD develop FTTDCD beyond the neonatal period and/or citrullinemia type II in adulthood, while the majority remains asymptomatic in later life [18]. Herein we report on two siblings, of whom the first was diagnosed with typical symptoms at the age of 8 weeks, while the younger brother was diagnosed immediately after birth. Both children responded well to dietary treatment, and patient 2 even remained asymptomatic.

\section{Case presentations}

\section{Patient 1}

The patient is the second child of non-consanguineous parents. The father is of Vietnamese origin, the mother of Romanian ancestry. The 2-year-old sister is healthy. The girl was born at 38 gestational weeks after an uneventful pregnancy. Her birth weight was $2770 \mathrm{~g}$, birth length $48 \mathrm{~cm}$, and head circumference $32 \mathrm{~cm}$, Apgar 10/ 10. The family was discharged from hospital on day 4 , but the girl presented again on day 8 with neonatal icterus (total bilirubin $21.2 \mathrm{mg} / \mathrm{dl}$, direct bilirubin $0.8 \mathrm{mg}$ / dl) requiring phototherapy. Apart from hyperbilirubinemia the clinical condition was very good, and the girl was fully breastfed. Phototherapy could be terminated after $23 \mathrm{~h}$ and bilirubin levels remained stable thereafter.

At the age of 8 weeks the child presented to the local pediatrician with a mild febrile airway infection. The girl was severely icteric but otherwise still in good clinical condition. The mother reported that the child required feeding every other hour, also at night. No stool or urine abnormalities were observed. She was admitted to the hospital for further diagnostic work-up. Laboratory testing revealed hepatopathy with the following parameters: prothrombin time $40 \%$, INR 1.64, partial thromboplastin time $41 \mathrm{~s}$., fibrinogen $63 \mathrm{mg} / \mathrm{dL}$ (normal 130-330 mg/ $\mathrm{dL}$ ), antithrombin 35\%, AST $86 \mathrm{U} / \mathrm{L}$ (normal 10-35 U/ L), ALT $28 \mathrm{U} / \mathrm{L}$ (normal 10-35 U/L), alkaline phosphatase $1367 \mathrm{U} / \mathrm{L}$ (normal < $449 \mathrm{U} / \mathrm{L}$ ), gamma-GT $149 \mathrm{U} / \mathrm{L}$ (8-178 U/L), total bilirubin $10.2 \mathrm{mg} / \mathrm{dL}$ (normal $<1 \mathrm{mg}$ ) $\mathrm{dL}$ ), direct bilirubin $4.9 \mathrm{mg} / \mathrm{dL}$ (normal $<0.3 \mathrm{mg} / \mathrm{dL}$ ), total protein $4.0 \mathrm{~g} / \mathrm{dL}$ (normal $4.4-7.6 \mathrm{~g} / \mathrm{dL}$ ), albumin $2.7 \mathrm{~g} / \mathrm{dL}$ (normal $3.8-5.4 \mathrm{~g} / \mathrm{dL}$ ), alpha-fetoprotein $>12,000 \mathrm{ng} / \mathrm{mL}$ (normal $<77 \mathrm{ng} / \mathrm{mL}$ ), and ferritin $1402 \mathrm{ng} / \mathrm{mL}$ (normal
15-150 ng/mL). The blood count was normal, and there were no signs of infection (CRP $3.4 \mathrm{mg} / \mathrm{dL}$, normal $<3$ $\mathrm{mg} / \mathrm{dL}$ ). Blood gas analysis yielded an elevated lactate concentration of $6.1 \mathrm{mmol} / \mathrm{L}$. Ammonia concentration was $123 \mu \mathrm{mol} / \mathrm{L}$ (normal < $70 \mu \mathrm{mol} / \mathrm{L}$ ).

Abdominal ultrasound showed liver size at the upper normal limit with enhanced echogenicity. No splenomegaly was detected, and the gall bladder as well as the bile ducts were normal. Polymerase chain reaction (PCR) analyses for $\mathrm{CMV}$, enterovirus and parechovirus were negative, and toxoplasmosis was excluded serologically. Immunological investigations were not suggestive for immunological causes of the hepatopathy. Elastase concentration in stool was normal, and newborn screening for cystic fibrosis was unremarkable. Ultrasound of the brain, electrocardiogram and echocardiography were unremarkable.

During the following days the child displayed recurrent episodes of asymptomatic severe hypoglycemia with minimal glucose concentrations of $1.3 \mathrm{mmol} / \mathrm{L}$ despite frequent feeding (every $2 \mathrm{~h}$ ). Lactate concentrations ranged from 0.9 to $6.1 \mathrm{mmol} / \mathrm{L}$.

Metabolic investigations were interpreted as not suggestive of a specific disorder. Organic acids in urine showed massive tyrosyluria, well compatible with hepatopathy. Acylcarnitine analysis in dried blood spots yielded an elevated concentration of free carnitine with unspecifically elevated levels of several acylcarnitines. Amino acid analysis showed elevated concentrations of several amino acids including citrulline $(331 \mu \mathrm{mol} / \mathrm{L}$, normal $<35 \mu \mathrm{mol} / \mathrm{L}$ ). The sialotransferrin pattern (screening for congenital disorders of glycosylation) was normal.

Due to the trias of hepatopathy/impaired hepatic function, lactic acidosis and recurrent hypoglycemia a hepatic form of a mitochondrial depletion syndrome was initially suspected, especially in combination with the markedly elevated concentrations of alpha fetoprotein and ferritin. Clinically, no neurologic involvement was observed, and the brain MRI showed unremarkable results. To prevent hypoglycemia breast milk was supplemented with MCT oil and maltodextrin. After 2 weeks, the child had to be transferred to the intensive care unit due to severe recurrent hypoglycemia. In the end, normal blood glucose levels could only be achieved by continuous i.v. glucose infusion or continuous oral feeding. Therefore, a percutaneous endoscopic gastrostomy (PEG) tube was inserted to enable normoglycemia and discharge from the hospital. Due to major PEG tube complications and a suspected intestinal perforation followed by a systemic infection inpatient treatment was prolonged. Lactate levels during this episode increased to $17 \mathrm{mmol} / \mathrm{L}$. In the meanwhile, results of trio exome sequencing became available and revealed two mutations in the SLC25A13 gene, one frameshift variant c.852 
855del, p.Met285Profs*2 and a novel deletion c. $(69+1$ 70-1)_(212+1_231-1)del, p.?. The father was found heterozygous for the frameshift variant by Sanger sequencing, whereas the mother is a carrier of the deletion, confirmed by qPCR.

Since several attempts to implement tube-feeding with tea or small amounts of breast milk resulted in severe deterioration of abdominal symptoms, the PEG tube was removed after 3 weeks. Explorative laparotomy revealed extensive adhesions of the small intestine but no perforation. After removal of the PEG tube, the clinical condition stabilised and oral feeding could successfully be reintroduced. The child received a galactose-free, carbohydrate reduced, MCT-enriched diet consisting of Pregomin Proexpert (Milupa) and Basic-ch (Nutricia) (composition of nutrients displayed in Fig. 1). Under this regimen blood glucose levels remained stable with feeding intervals of $4 \mathrm{~h}$. Hepatopathy and cholestasis resolved apart from a persistent mild elevation of transaminase activities. Lactate levels also normalised. At the age of 4 months the patient could be discharged from hospital in good clinical condition. Blood glucose monitoring at home revealed no further hypoglycemia.

At the age of 6 months, supplementary foods were started without any complications. The diet was still galactose-free, carbohydrate-reduced and rich in protein and MCT. The girl is now 2 years old and shows normal psychomotor development. The only pathological findings are slightly elevated transaminase activities. Relevant laboratory parameters during the course of the disease are shown in Fig. 2.

\section{Patient 2}

One year later her younger brother was born. Genetic testing was initiated immediately after birth. Until the results became available, a diet consisting of $50 \%$ breast milk and 50\% Pregomin Proexpert (lactose-free, 50\% MCT fat) was recommended. On day $12, \mathrm{CD}$ was genetically confirmed by Sanger sequencing for the paternal mutation and qPCR for the maternal mutation. A lactose-free, MCT-enriched diet was started on the same day. He clinically remained asymptomatic with no signs of cholestasis or icterus. Laboratory monitoring was performed at age 4, 7, 13 and 18 weeks. Results of liver enzymes, bilirubin and total protein concentrations are displayed in Fig. 3.

\section{Newborn screening}

$\mathrm{CD}$ is not a target disease of newborn screening programs in Germany. Nevertheless, citrulline levels as well as the levels of other diagnostic amino acids are measured in dried blood spots. Results of the amino acids measured by tandem mass spectrometry in the dried blood spots of the newborn screening samples of our two patients are displayed in Table 1 .

\section{Discussion and conclusions}

We report on 2 siblings with compound heterozygosity for two variants in the SLC25A13 gene of whom the index patient presented with cholestasis at age 8 weeks while in the younger brother clinical symptoms were possibly prevented by early initiation of a specific diet. The main findings in our patient apart from hepatopathy were severe recurrent hypoglycemia and elevated lactate concentrations. Both hypoglycemia and hyperlactatemia are no common biochemical abnormalities in patients with NICCD [11], although hypoglycemia has been reported in few patients $[12,16,18,19]$. The pathophysiology of hypoglycemia in $\mathrm{CD}$ is not well understood. Young children are prone to develop hypoglycemia relatively easily due to CD-related suppression of gluconeogenesis [20]. It has additionally been suggested that severe hypoglycemia in patients with $\mathrm{CD}$ could be associated with relatively low levels of ketone bodies, implying that $\beta$-oxidation and ketogenesis in these patients might possibly be partially disrupted [19] due to altered redox states and PPAR dysregulation. The diagnosis of $\mathrm{CD}$ in our patient 1 was slightly delayed as the clinical

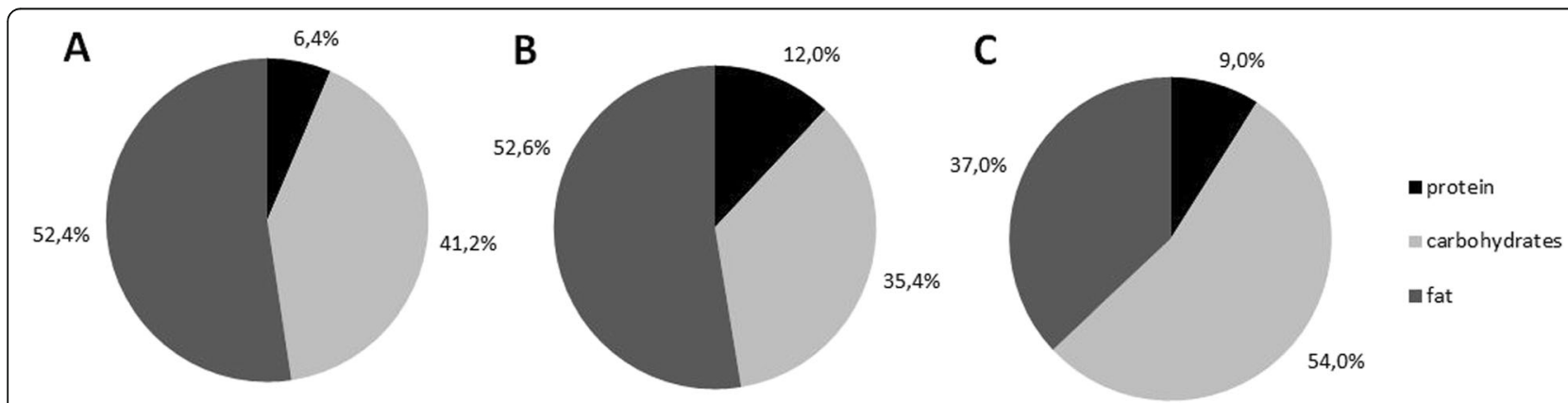

Fig. 1 Comparison of relative nutrient intakes (proportion of total energy intake). a Average intake of a fully breast-fed child (b) Recommendation for our patient since diagnosis of CD. $35-46 \%$ of the fat intake was provided as MCT fat. c Average nutrient intake of a 1-year-old healthy child as recommended by the German Nutrition Society (DGE) 

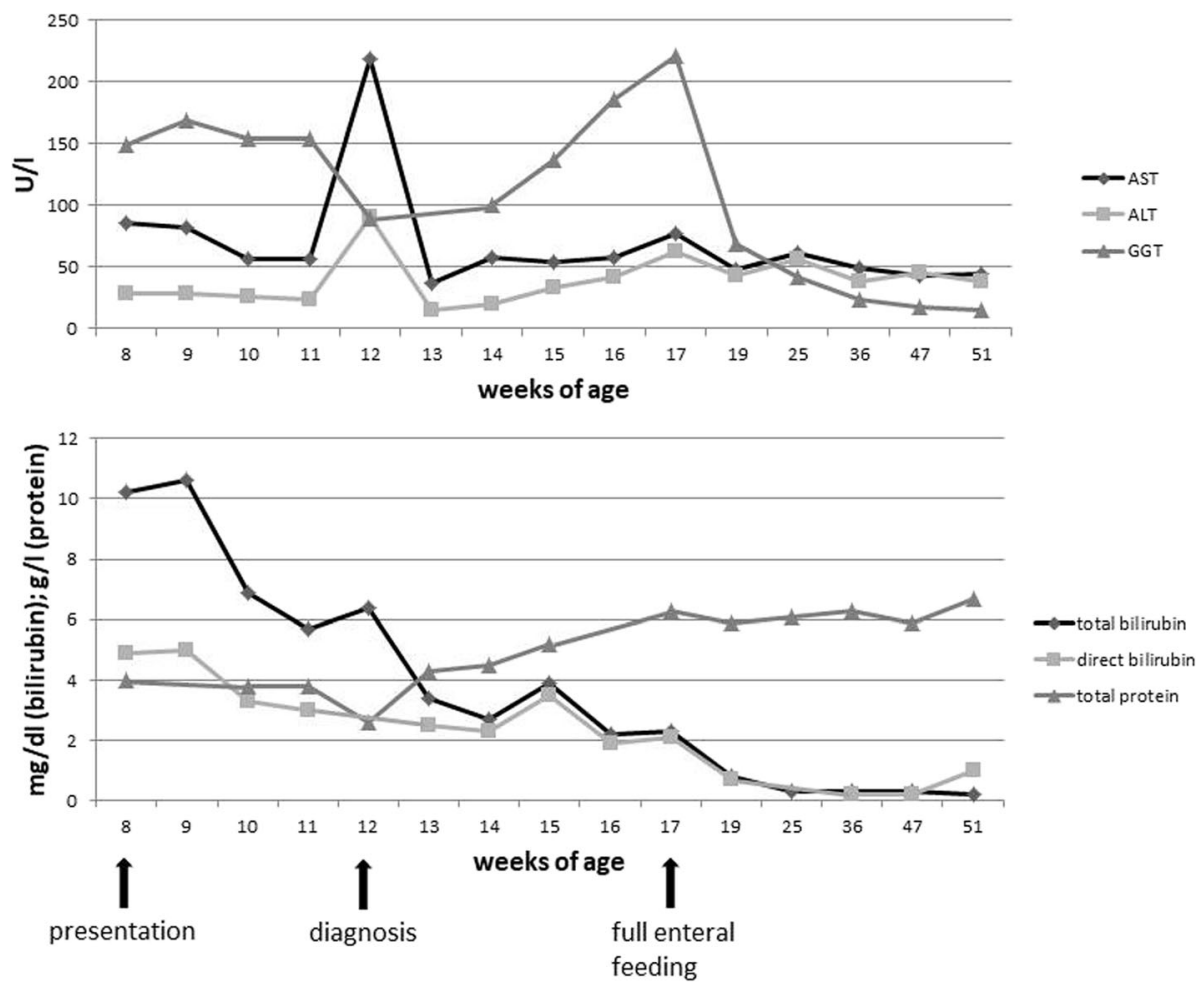

Fig. 2 Laboratory parameters in the clinical course of patient 1 from presentation (8 weeks) until the age of 1 year

picture was primarily suggestive of a hepatic form of a mitochondrial depletion syndrome, in particular DGUOK deficiency due to the markedly elevated levels of alpha fetoprotein and ferritin [21], and diagnosis was finally made by whole exome sequencing. Of the two mutations found in our patient, the c.852_855del, p.Met285Profs" 2 variant is very common in Asian populations and derived from the father who was of Vietnamese origin [19, 22-24].

The second mutation, c. $\left(69+1 \_70-1\right) \_\left(212+1 \_231-\right.$ 1)del, has not been described previously, and the consequences of this variant on protein level are not known. However, since the deletion encompasses exon 3 of the SLC25A13 gene, it is well conceivable that this variant is deleterious. In Europe, $\mathrm{CD}$ is an extremely rare inborn error of metabolism. However, globalisation and the concomitant worldwide spread of Asian populations will increase the likelihood of identifying more cases of NICCD outside the classical distribution area for CD [25]. This highlights the importance for pediatricians and metabolic physicians of being aware of $\mathrm{CD}$ as a differential diagnosis of neonatal cholestasis.

NICCD usually responds very well to dietary treatment and clinical symptoms resolve within months. This was also true for our patient 1 who showed an immediate response to dietary adaptations with resolution of hypoglycaemia and cholestasis. Nevertheless, few severe (requiring liver transplantation) or even fatal cases have been reported [13-15, 26, 27]. Abuduxikuer et al. investigated a cohort of 61 confirmed NICCD cases for risk factors associated with mortality [27]. Comparing 52 cases in the survival group with 9 fatal cases of NICCD the authors identified late referral, presence of infection, delayed treatment with lactose-free/MCT formula, lower platelet count, lower levels of gamma-GT, total cholesterol and blood citrulline and higher blood concentrations of ammonia and tyrosine as factors associated with poor prognosis [27].

Most patients with CD show a particular food preference from early childhood with a natural aversion against carbohydrate-rich foods and a strong preference for protein- and fat-rich foods, which is very different from the well-known aversion to protein among patients with other urea cycle defects $[1,16]$. Saheki et al. studied the food intake of 18 Japanese citrin-deficient subjects with an age range from 1 to 33 years [4]. They found that the average relative fat and protein intake was higher in $\mathrm{CD}$ patients compared with published values for the general Japanese population with 134 and $116 \%$, respectively. In contrast, the average relative carbohydrate intake was only $56 \%$ of age- and sex-matched Japanese controls. Carbohydrate, fat and protein provided 37,44 and $19 \%$ of total energy in CD patients compared to $56,27.5$ and $14.5 \%$ in the healthy population. The 

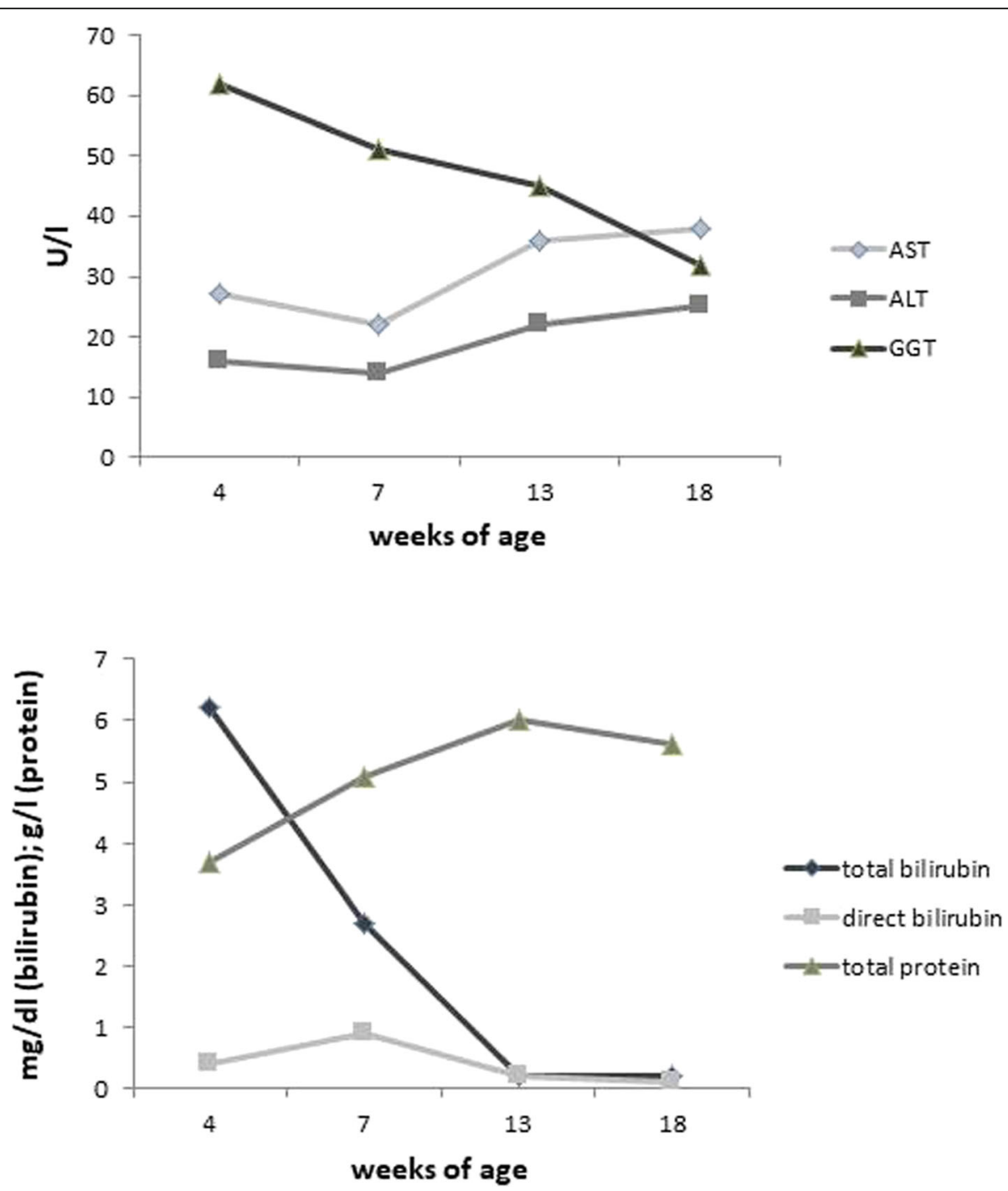

Fig. 3 Laboratory parameters in the clinical course of patient 2 from birth until the age of 18 weeks

peculiar food preferences may start from as early as 1 year of age, but they can take some time to be recognized by caregivers [4]. Nevertheless, food preferences may be a diagnostic hint for $\mathrm{CD}$, even in the absence of other signs and symptoms $[4,19]$ and should prompt clinicians to rule out $\mathrm{CD}[4,19]$.

Studies in animal models of CD have provided insights into possible mechanisms for reduced carbohydrate intake. Double knockout mice for mitochondrial glycerol-3- phosphate dehydrogenase and citrin, a phenotypic model for human $\mathrm{CD}$, showed oral aversion to dietary sugar, ethanol and glycerol that correlated with alterations in specific hepatic metabolites [28]. The authors conclude that the aversion observed in the double-KO mice is mediated by hepatic metabolic perturbations, resulting in a behavioral response to

Table 1 Relevant amino acid results measured by tandem mass spectrometry in dried blood spots newborn screening samples of both patients

\begin{tabular}{llll}
\hline Parameter & Patient $\mathbf{1}$ & Patient 2 & Reference range $(\boldsymbol{\mu m o l} / \mathbf{L})$ \\
\hline citrulline $(\mu \mathrm{mol} / \mathrm{L})$ & 49 & 51 & $6-91.63$ \\
tyrosine $(\mu \mathrm{mol} / \mathrm{L})$ & 49 & 32 & $<350$ \\
phenylalanine $(\mu \mathrm{mol} / \mathrm{L})$ & 38 & 32 & $<123$ \\
alanine/citrulline ratio & 3.18 & 3.86 & n.a. \\
\hline
\end{tabular}


increased hepatic cytosolic NADH and a decreased cellular adenine nucleotide pool [28]. The same findings may underlie the dietary predilections observed in $\mathrm{CD}$ patients. Under normal conditions, an increase in cytosolic NADH/NAD+ ratio following a carbohydrate-rich meal is relieved by NADH shuttle activity via the malate-aspartate and/or glycerol phosphate shuttles. Saheki et al. postulated that in CD patients the citrin defect leads to inhibition of ureagenesis by limiting the supply of aspartate for the urea cycle. This is not only due to the lack of aspartate supplied from mitochondria, but also because a high cytosolic NADH/NAD+ ratio reduces the cytosolic oxaloacetate concentration resulting in a shortage of cystosolic aspartate [4]. By reducing the intake of carbohydrates, CD patients can effectively minimize this deficiency of aspartate [4]. These pathophysiological considerations explain why some of the conventional treatment procedures for urea cycle defects/hyperammonemia may be very harmful in individuals with $\mathrm{CD}$. A low-protein carbohydrate-rich diet is the standard therapy of urea cycle defects. However, if given to a patient with $\mathrm{CD}$, this may cause severe metabolic disturbances such as hyperammonemia and hyperlipidemia [18, 29]. Similarly, high glucose or glycerol infusions (i.e. for brain edema) may result in severe clinical deterioration or even death in patients with CTNL2 [30-32]. Mutoh et al. reported that some Japanese children with $C D$ have become severely ill after the entrance into primary school, where all school children had to take a high-carbohydrate lunch provided by the school [33]. These examples underline the importance of caregivers to respect the CD-typical food preferences to avoid clinical decompensations.

Tandem mass spectrometry-based newborn screening for $\mathrm{CD}$ is performed in certain countries with a high incidence of CD [34, 35]. Elevated citrulline levels and several citrulline-based ratios are the primary screening markers. However, it is known that citrulline levels in children with NICCD may not be elevated immediately after birth and several cases missed by newborn screening have been reported $[13,19,36]$. In a recent study with 55 patients with genetically proven NICCD, only 18 cases $(18 / 55,32.7 \%)$ were true positives and 37 cases $(37 / 55,67.3 \%)$ were false negatives based on the cut off value for citrulline in dried blood spots in newborn screening [35]. Blood sampling time seems to have an influence on the sensitivity of NICCD newborn screening, and false negative results were more common in the group of very early-screened patients. The citrulline levels in the newborn screening samples of our two patients were also normal. However, as $\mathrm{CD}$ is not a target disease of German newborn screening programs, cut off values established for the diagnosis of citrullinemia type 1 were used in our patients (displayed in Table 1) [37].
Clinical laboratory studies from countries with high incidence of $C D$ have established lower cut-off values for citrulline in newborn screening $[34,38]$. To improve the detection rate of NICCD in newborn screening the combined use of low citrulline cut offs together with second tier genetic screening has been suggested as the optimal strategy [34].

Since the treatment of citrullinemia type 1 and CD are very different and a protein-reduced, carbohydrateenriched diet as suggested in citrullinemia type 1 aggravates symptoms in $C D$, a clear discrimination is essential directly after the newborn screening results have become available. This is sometimes challenging since mild forms of citrullinemia type 1 may only present with elevated citrulline without elevation of glutamine.

As CD is a well-treatable disorder this metabolic defect should be ruled out early in every infant with hepatic cholestasis and should also be considered in screened patients with mild elevations of citrulline. It is important to recognize that hypoglycemia can be part of the biochemical phenotype and that the clinical presentation may mimic hepatic mitochondrial depletion syndrome.

\section{Abbreviations \\ CD: Citrin deficiency; NICCD: Neonatal intrahepatic cholestasis caused by citrin deficiency; MCT: Middle-chain triglycerides; PCR: Polymerase chain reaction; PEG: Percutaneous endoscopic gastrostomy}

\section{Acknowledgements}

This work was supported in part by the Center for Metabolic Diseases, Freiburg Center for Rare Diseases. Several authors of this publication are members of the European Reference Network for Rare Hereditary Metabolic Disorders (MetabERN) - Project ID No 739543.

\section{Authors' contributions}

SCG was responsible for the diagnostic work-up and treatment of both patients and drafted the manuscript including all tables and Figs. AS, SRF, MS, HS, HF, UT, LH and US were involved in the diagnosis and/or clinical care of the patients and critically revised the manuscript. PF gave advise in the diagnostic process and management of the patient. SBW and AJM performed whole exome screening and interpretation of the results. TBH supervised the molecular work. GG performed newborn screening in both patients. All authors read and critically revised the manuscript.

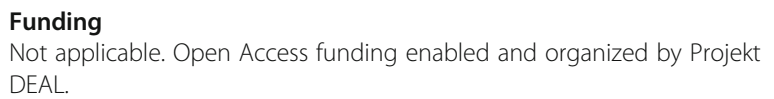

Availability of data and materials

Not applicable.

Ethics approval and consent to participate

Not applicable.

Consent for publication

The patients' parents gave their written informed consent for the publication of this report.

Competing interests

The authors declare that they have no competing interests. 


\section{Author details}

'Department of General Paediatrics, Adolescent Medicine and Neonatology, Medical Centre-University of Freiburg, Faculty of Medicine, Mathildenstraße 1, 79106 Freiburg, Germany. ${ }^{2}$ Department of Paediatrics, Klinikum Reutlingen, 72764 Reutlingen, Germany. ${ }^{3}$ Institute of Medical Genetics and Applied Genomics, University of Tübingen, Tübingen, Germany. ${ }^{4}$ Center for Rare Diseases, University of Tübingen, 72076 Tübingen, Germany. ${ }^{5}$ University Hospital Heidelberg, Centre for Paediatric and Adolescent Medicine, Division of Neuropaediatrics and Metabolic Medicine, Im Neuenheimer Feld 430, 69120 Heidelberg, Germany. ${ }^{6}$ Department of General Paediatrics, Adolescent Medicine and Neonatology, Laboratory of Clinical Biochemistry and Metabolism, Medical Centre-University of Freiburg, Faculty of Medicine, Freiburg, Germany.

\section{Received: 4 September 2020 Accepted: 30 October 2020} Published online: 11 November 2020

\section{References}

1. Saheki T, Inoue K, Tushima A, Mutoh K, Kobayashi K. Citrin deficiency and current treatment concepts. Mol Genet Metab. 2010;100(Suppl 1):S59-64.

2. Saheki T, Song Y-Z. Citrin deficiency. In: Adam MP, Ardinger HH, Pagon RA, Wallace SE, Bean LJ, Stephens K, et al., editors. GeneReviews ${ }^{\oplus}$. Seattle: University of Washington, Seattle; 1993. http://www.ncbi.nlm.nih.gov/books/ NBK1181/. Accessed 7 Mar 2020.

3. Saheki T, Kobayashi K. Mitochondrial aspartate glutamate carrier (citrin) deficiency as the cause of adult-onset type ॥ citrullinemia (CTLN2) and idiopathic neonatal hepatitis (NICCD). J Hum Genet. 2002;47:333-41.

4. Saheki T, Kobayashi K, Terashi M, Ohura T, Yanagawa Y, Okano Y, et al. Reduced carbohydrate intake in citrin-deficient subjects. J Inherit Metab Dis. 2008;31:386-94.

5. Palmieri L, Pardo B, Lasorsa FM, del Arco A, Kobayashi K, lijima M, et al. Citrin and aralar1 are $\mathrm{Ca}(2+)$-stimulated aspartate/glutamate transporters in mitochondria. EMBO J. 2001;20:5060-9.

6. Dimmock D, Maranda B, Dionisi-Vici C, Wang J, Kleppe S, Fiermonte G, et al. Citrin deficiency, a perplexing global disorder. Mol Genet Metab. 2009;96:44-9.

7. Dimmock D, Kobayashi K, lijima M, Tabata A, Wong L-J, Saheki T, et al. Citrin deficiency: a novel cause of failure to thrive that responds to a high-protein, low-carbohydrate diet. Pediatrics. 2007;119:e773-7.

8. Ben-Shalom E, Kobayashi K, Shaag A, Yasuda T, Gao H-Z, Saheki T, et al. Infantile citrullinemia caused by citrin deficiency with increased dibasic amino acids. Mol Genet Metab. 2002;77:202-8.

9. Hutchin T, Preece MA, Hendriksz C, Chakrapani A, McClelland V, Okumura F, et al. Neonatal intrahepatic cholestasis caused by citrin deficiency (NICCD) as a cause of liver disease in infants in the UK. J Inherit Metab Dis. 2009; 32(Suppl 1):S151-5.

10. Fiermonte G, Soon D, Chaudhuri A, Paradies E, Lee PJ, Krywawych S, et al. An adult with type 2 citrullinemia presenting in Europe. N Engl J Med. 2008; 358:1408-9.

11. Wang J-S, Wang $X-H$, Zheng $Y-J, F u ~ H-Y$, Chen R, Lu Y, et al. Biochemical characteristics of neonatal cholestasis induced by citrin deficiency. World J Gastroenterol. 2012;18:5601-7.

12. Ohura T, Kobayashi K, Tazawa Y, Abukawa D, Sakamoto O, Tsuchiya S, et al. Clinical pictures of 75 patients with neonatal intrahepatic cholestasis caused by citrin deficiency (NICCD). J Inherit Metab Dis. 2007;30:139-44.

13. Tamamori A, Okano Y, Ozaki H, Fujimoto A, Kajiwara M, Fukuda K, et al. Neonatal intrahepatic cholestasis caused by citrin deficiency: severe hepatic dysfunction in an infant requiring liver transplantation. Eur J Pediatr. 2002; 161:609-13.

14. Shigeta T, Kasahara M, Kimura T, Fukuda A, Sasaki K, Arai K, et al. Liver transplantation for an infant with neonatal intrahepatic cholestasis caused by citrin deficiency using heterozygote living donor. Pediatr Transplant. 2010;14:E86-8

15. Zhao X-J, Tang X-M, Zha Q-B, Shi S-S, Song Y-Z, Xiao X-M. Prenatal diagnosis of citrin deficiency in a Chinese family with a fatal proband. Tohoku J Exp Med. 2011;225:273-6.

16. Okano $Y$, Ohura $T$, Sakamoto $O$, Inui A. Current treatment for citrin deficiency during NICCD and adaptation/compensation stages: strategy to prevent CTLN2. Mol Genet Metab. 2019;127:175-83.

17. Hachisu M, Oda Y, Goto M, Kobayashi K, Saheki T, Ohura T, et al. Citrin deficiency presenting with ketotic hypoglycaemia and hepatomegaly in childhood. Eur J Pediatr. 2005;164:109-10.
18. Saheki T, Kobayashi K, lijima M, Moriyama M, Yazaki M, Takei Y-I, et al. Metabolic derangements in deficiency of citrin, a liver-type mitochondrial aspartate-glutamate carrier. Hepatol Res. 2005;33:181-4.

19. Chong SC, Lo P, Chow CW, Yuen L, Chu WCW, Leung TY, et al. Molecular and clinical characterization of citrin deficiency in a cohort of Chinese patients in Hong Kong. Mol Genet Metab Rep. 2018;17:3-8.

20. Wada Y, Arai-Ichinoi N, Kikuchi A, Sakamoto O, Kure S. Hypoketotic hypoglycemia in citrin deficiency: a case report. BMC Pediatr. 2020;20:444

21. Freisinger $P$, Fütterer $N$, Lankes $E$, Gempel K, Berger TM, Spalinger J, et al. Hepatocerebral mitochondrial DNA depletion syndrome caused by deoxyguanosine kinase (DGUOK) mutations. Arch Neurol. 2006;63:1129-34

22. Song Y-Z, Deng M, Chen F-P, Wen F, Guo L, Cao S-L, et al. Genotypic and phenotypic features of citrin deficiency: five-year experience in a Chinese pediatric center. Int J Mol Med. 2011;28:33-40.

23. Lin $\mathrm{W}-\mathrm{X}$, Zeng $\mathrm{H}-\mathrm{S}$, Zhang Z-H, Mao M, Zheng Q-Q, Zhao S-T, et al. Molecular diagnosis of pediatric patients with citrin deficiency in China: SLC25A13 mutation spectrum and the geographic distribution. Sci Rep. 2016;6:29732

24. Fu H-Y, Zhang S-R, Wang X-H, Saheki T, Kobayashi K, Wang J-S. The mutation spectrum of the SLC25A13 gene in Chinese infants with intrahepatic cholestasis and aminoacidemia. J Gastroenterol. 2011;46:510-8.

25. Vitoria I, Dalmau J, Ribes C, Rausell D, García AM, López-Montiel J, et al. Citrin deficiency in a Romanian child living in Spain highlights the worldwide distribution of this defect and illustrates the value of nutritional therapy. Mol Genet Metab. 2013;110:181-3.

26. Zhang Z-H, Yang Z-G, Chen F-P, Kikuchi A, Liu Z-H, Kuang L-Z, et al. Screening for five prevalent mutations of SLC25A13 gene in Guangdong, China: a molecular epidemiologic survey of citrin deficiency. Tohoku J Exp Med. 2014:233:275-81.

27. Abuduxikuer K, Chen R, Wang Z-L, Wang J-S. Risk factors associated with mortality in neonatal intrahepatic cholestasis caused by citrin deficiency (NICCD) and clinical implications. BMC Pediatr. 2019;19:18.

28. Saheki T, Inoue $K$, Ono H, Fujimoto Y, Furuie S, Yamamura K-I, et al. Oral aversion to dietary sugar, ethanol and glycerol correlates with alterations in specific hepatic metabolites in a mouse model of human citrin deficiency. Mol Genet Metab. 2017;120:306-16

29. Imamura Y, Kobayashi K, Shibatou T, Aburada S, Tahara K, Kubozono O, et al Effectiveness of carbohydrate-restricted diet and arginine granules therapy for adult-onset type II citrullinemia: a case report of siblings showing homozygous SLC25A13 mutation with and without the disease. Hepato Res. 2003;26:68-72.

30. Takahashi H, Kagawa T, Kobayashi K, Hirabayashi H, Yui M, Begum L, et al. A case of adult-onset type II citrullinemia--deterioration of clinical course after infusion of hyperosmotic and high sugar solutions. Med Sci Monit. 2006;12:CS13-5.

31. Yazaki M, Takei Y, Kobayashi K, Saheki T, Ikeda S. Risk of worsened encephalopathy after intravenous glycerol therapy in patients with adultonset type II citrullinemia (CTLN2). Intern Med. 2005;44:188-95.

32. Fukushima K, Yazaki M, Nakamura M, Tanaka N, Kobayashi K, Saheki T, et al. Conventional diet therapy for hyperammonemia is risky in the treatment of hepatic encephalopathy associated with citrin deficiency. Intern Med. 2010;49:243-7.

33. Mutoh K, Kurokawa K, Kobayashi K, Saheki T. Treatment of a citrin-deficient patient at the early stage of adult-onset type $\|$ citrullinaemia with arginine and sodium pyruvate. J Inherit Metab Dis. 2008;31(Suppl 2):S343-7.

34. Lin Y, Liu Y, Zhu L, Le K, Shen Y, Yang C, et al. Combining newborn metabolic and genetic screening for neonatal intrahepatic cholestasis caused by citrin deficiency. J Inherit Metab Dis. 2019;43(3):467.

35. Tang CF, Liu SC, Feng Y, Mei HF, Liu HP, Feng JW, et al. Newborn screening program and blood amino acid profiling in early neonates with citrin deficiency. Zhonghua Er Ke Za Zhi. 2019;57:797-801.

36. Estrella J, Wilcken B, Carpenter K, Bhattacharya K, Tchan M, Wiley V. Expanded newborn screening in New South Wales: missed cases. J Inherit Metab Dis. 2014;37:881-7.

37. Sander J, Janzen N, Sander S, Steuerwald U, Das AM, Scholl S, et al. Neonatal screening for citrullinaemia. Eur J Pediatr. 2003;162:417-20.

38. Tamamori A, Fujimoto A, Okano Y, Kobayashi K, Saheki T, Tagami Y, et al. Effects of citrin deficiency in the perinatal period: feasibility of newborn mass screening for citrin deficiency. Pediatr Res. 2004;56:608-14.

\section{Publisher's Note}

Springer Nature remains neutral with regard to jurisdictional claims in published maps and institutional affiliations. 